\title{
Parents' Degree and Style of Restrictive Mediation of Young Children's Digital Gaming: Associations with Parental Attitudes and Perceived Child Adjustment
}

Stijn Van Petegem ${ }^{1}$, Evelien de Ferrerre ${ }^{2}$, Bart Soenens ${ }^{3}$, Antonius J. van Rooij ${ }^{2,4} \&$ Jan Van Looy ${ }^{2}$

${ }^{1}$ Family and Development Research Center (FADO), Institute of Psychology

University of Lausanne, Switzerland

${ }^{2}$ Research group for Media \& ICT, Department communication sciences

iMinds - MICT - Ghent University, Belgium

${ }^{3}$ Department Of Developmental, Personality, and Social Psychology

Ghent University, Belgium

${ }^{4}$ Department of Youth \& Risky Behavior

Trimbos Institute, The Netherlands

This article may not exactly replicate the final version published in the journal. The final version is in press in Journal of Child and Family Studies.

The exact reference is: Van Petegem, S., de Ferrerre, E., Soenens, B., van Rooij, T. J., \& Van Looy, J. (2019). Parents' degree and style of restrictive mediation in young children's digital gaming: Associations with parental attitudes and perceived child adjustment. Journal of Child and Family Studies, 28, 1379-1391. 


\begin{abstract}
Objectives. As young children increasingly grow up in a digital environment, parents are confronted with the question whether and how to regulate young children's digital gaming effectively. The goal of this study was to examine correlates of parents' degree of restrictive mediation and their (autonomy-supportive or controlling) style of doing so. Specifically, we tested associations of parents' degree and style of restrictive mediation with parents' attitudes about digital gaming, parental perceptions of children's defiance and problematic gaming, and their interest in social play.
\end{abstract}

Methods. A sample of 762 parents of children between 3 and 9 years filled out questionnaires on their degree and style of restrictive mediation, their attitudes about gaming, and their perceptions of children's oppositional defiance, problematic gaming, and interest in social play.

Results. We found that parents who hold more negative attitudes about digital gaming were more likely to use a controlling style when mediating their child's gaming. Further, a higher degree of restrictive mediation generally related to more adaptive child outcomes (i.e., lower levels of perceived defiance and problematic gaming, higher levels of perceived interest in social play), whereas the opposite pattern was found for parents' controlling style of mediation. Finally, these associations were not moderated by children's age or gender, nor by parents' gender or educational level.

Conclusions. Also in the context of children's digital gaming, it seems important for parents to set clear rules. Yet, when doing so, it is equally important to refrain from using controlling strategies, as they seem to be counterproductive.

Keywords: parental mediation, digital gaming, autonomy support, control 
The advent of easy-to-use, touch-enabled devices such as tablets and smartphones has given rise to a large ecosystem of digital applications and content for young children and to widespread use of digital media by this group (Gutnick, Robb, Takeuchi, \& Kotler, 2010; Wartella, Rideout, Lauricella, \& Connell, 2013). Indeed, the growing presence of touchscreen devices strongly increases young children's media consumption and their gaming behavior in particular. Developmentally speaking, gaming behavior is a double-edged sword with both advantages and disadvantages (Granic, Lobel \& Engels, 2014; Przybylski \& Weinstein, 2017a, 2017b). On the positive side, gaming devices support the sensory and motor skills of very young children; skills that in turn facilitate children's independent use of these devices (Holloway, Green, \& Livingstone, 2013) and their problem-solving skills more generally (Adachi \& Willoughby, 2013). On the negative side, parents may be concerned that time spent gaming comes at the cost of real-life social interaction and physical activity. They may also worry about certain types of content displayed in games (e.g., violence, sexuality; for debates on these issues, see for instance Ferguson, 2013, 2015a; Ferguson \& Konijn, 2015; Scharrer, 2004).

However, as young children have limited ability to assess the appropriateness of media content (Livingstone, Görzig, \& Ólafsson, 2011) and because parents generally are highly involved in children's lives (Clark, 2011), parents have an important role in managing their young children's media consumption (Livingstone, 2007; Radesky, Schumacher, \& Zuckerman, 2015; Zaman \& Mifsud, 2017). One specific and intensively studied way in which parents can be involved in children's digital media use is through restrictive mediation, which refers parents' setting of rules, supervision, and regulation of children's media use (Livingstone \& Helsper, 2008; Nathanson, 2001; Nikken \& Jansz, 2003, 2006). So far, research on parental restrictive mediation of digital gaming primarily focused on adolescents (e.g., Coyne, Padilla-Walker, Stockdale, \& Day, 2011; Holtz \& Appel, 2011; for an exception, see Nikken \& Schols, 2015). However, Radesky et al. (2015) emphasized the urgent need for more research on young children's device use and on parents' role in guiding their children in an age-appropriate way.

When considering parents' restrictive mediation, it seems important for parents to set clear limits and regulate their children's media consumption so as to avoid a laissez-faire climate in which everything is permitted (e.g., Barber, Maughan, \& Olsen, 2005). This may be easier said than done, however. Indeed, parents' restrictions may also be counterproductive, if children experience such restrictions as intrusive, or if digital games are perceived as 'forbidden fruit' (e.g., Brehm, 1966). In the latter case, gaming may be a source of parent-child conflict and parental rule-setting even may result in an increase (rather than a decrease) in undesirable behavior. Previous research provided evidence for such 'boomerang' effects of parental rule-setting among young children, 
for instance in the context of the prohibition of certain types of food among children of 5 and 6 years old (Jansen, Mulkens, \& Jansen, 2007).

To better understand when parental rule-setting and restrictions are effective and when they are not, researchers drawing upon Self-Determination Theory (SDT; Ryan \& Deci, 2000) argue that the effectiveness of parents' regulation not only depends upon the quantity (or the degree) of rule-setting, but also upon the quality (or the style) of the parents' rule-setting, that is, the way in which parents communicate and follow up on rules (Grolnick, 2003; Joussemet, Landry, \& Koestner, 2008; Soenens \& Vansteenkiste, 2010). In the context of digital gaming, SDT has been particularly influential in understanding the motivational appeal of video games (e.g., Przybylski, Rigby, \& Ryan, 2010; Przybylski, Weinstein, Murayama, Lynch, \& Ryan, 2012; Ryan, Rigby, \& Przybylski, 2009). This theory also may be relevant for the specific issue of parental rule-setting in the context of gaming. This is because SDT proposes that it is important to consider the quality of parents' communication style for understanding the effectiveness of rule-setting, thereby distinguishing between an autonomy-supportive or a controlling style. An autonomy-supportive style is characterized by being empathic towards the child's perspective and offering choices where possible and useful. Furthermore, autonomy-supportive parents would give a meaningful and understandable explanation when choices are limited or when rules are set (Grolnick, 2003; Soenens, Vansteenkiste, \& Niemiec, 2009). Thus, parents can implement rules and restrict children's freedom in an autonomy-supportive way. A controlling communication style involves forcing the child to conform to the parents' demands. In other words, controlling parents would impose obedience and enforce their own opinion through the use of punishments, forceful language, or threats. Other examples of controlling strategies are guilt induction, shaming, and love withdrawal (e.g., Barber, 1996; Grolnick \& Pomerantz, 2009; Soenens \& Vansteenkiste, 2010).

According to SDT, an autonomy-supportive style would foster children's psychosocial development and the internalization of rules, whereas a controlling style would relate not only to maladjustment and symptoms of psychopathology, but also would elicit reactance against parental rules (Ryan \& Deci, 2000; Vansteenkiste \& Ryan, 2013). In line with such claims, a growing body of research offers evidence for the beneficial effects of a generally autonomy-supportive (vs. controlling) parenting style on children's and adolescents' development (for overviews, see for instance, Joussemet et al., 2008; Ryan, Deci, \& Vansteenkiste, 2016). In the context of rulesetting specifically, research (mainly conducted among adolescents) showed that an autonomy-supportive communication style relates to the internalization of parental rules, whereas a controlling communication style forestalls the acceptance of parental authority instead (e.g., Van Petegem et al., 2017a). 
Only few studies to date simultaneously examined the role of the degree and style of parental restrictive mediation in children's media use. This is unfortunate because a recent meta-analysis demonstrated low effect sizes for the associations between parental restrictive mediation as such and indicators of children's and adolescents' media use (Collier et al., 2016). Possibly, the quality of parents' communication style matters on top of the degree of parental mediation. A recent study among early adolescents (10-14 years) confirmed the usefulness of distinguishing between parents' degree and style of mediation in the context of media consumption in general (Valkenburg, Piotrowski, Hermanns, \& Leeuw, 2013). They found an inconsistent pattern of correlates for parents' perceived degree of mediation, with restrictive mediation being particularly associated with more family conflict. In contrast, an autonomy-supportive style consistently related positively to indicators of welladjusted functioning (i.e., less family conflict, more prosocial behavior, less antisocial behavior), whereas an opposite pattern of results was observed for a controlling style. Most likely, the distinction between parents' degree of restrictive mediation and their (autonomy-supportive or controlling) style of mediation may help to explain other inconsistent or seemingly contradictory findings in the literature.

One such inconsistent finding pertains to parents' beliefs about gaming. A number of previous studies examined associations between parents' mediation practices and their beliefs and attitudes about gaming (e.g., Oosting, de Kort, \& Ijsselsteijn, 2012; Shin \& Huh, 2011; Wartella et al., 2013). A common hypothesis in this work is that negative attitudes about gaming would be associated with higher levels of parental mediation, as parents would be motivated to use these mediation strategies to mitigate these assumed negative consequences of digital games. However, results are rather inconsistent. Some studies found that parents with more negative attitudes do display higher levels of restrictive mediation towards their 8-18-year old children (e.g., Nikken \& Jansz, 2006), whereas other studies among parents of adolescents (12-17 years) documented non-significant relations or even an opposite pattern (e.g., Livingstone \& Helsper, 2008; Oosting et al., 2012). We assume that these mixed results might be better understood by differentiating between the degree and style of parental mediation. That is, it may be expected that negative beliefs about digital games, such as the view that games threaten children's development, would be particularly associated with a more controlling and less autonomysupportive style of mediation. Past research indeed suggests that, when parents hold negative beliefs about the world (e.g., with the world being a threatening place for children), parents tend to engage in more controlling (and less autonomy-supportive) practices towards their 9-year old children, in an attempt to shield them from this potentially threatening world (Gurland \& Grolnick, 2005; see also Grolnick \& Seal, 2008). Hence, parents endorsing the belief that digital games threaten their child's development also might be more controlling when 
mediating their child's gaming, in an attempt to protect their child from these potentially harmful effects (cf. Böcking \& Böcking, 2009; Shin \& Huh, 2011).

In addition, parents' degree and style of gaming mediation may be differentially associated with the child's defiance (as perceived by parents) and with parents' perceptions that the child's gaming is problematic. Defiance refers to a blunt resistance against the parental rules and a tendency to do the opposite of what is expected (Vansteenkiste, Soenens, Van Petegem, \& Duriez, 2014; Van Petegem, Vansteenkiste, Soenens, Beyers, \& Aelterman, 2015b). Children's excessive gaming, on the other hand, refers to perceptions of addiction-like behavioral problems, including loss of control, intra- and interpersonal conflict over gaming, and withdrawal symptoms if the child is forced to quit (van Rooij, Schoenmakers, van den Eijnden, Vermulst, \& van de Mheen, 2012; for discussions on the existence and criteria of a "pathological gaming disorder", see e.g., Ferguson, Coulson, \& Barnett, 2011; Griffiths, Kuss, Lopez-Fernandez, \& Pontes, 2017; Van Rooij et al., 2018). A number of previous cross-sectional and longitudinal studies among adolescents (ranging in age between 12 and 20 years) examined associations between parents' degree and style of rule-setting and adolescents' defiance to these rules. Whereas parents' perceived degree of rule-setting typically was found to be unrelated to defiance, a controlling communication style consistently related to more defiance, whereas an autonomy-supportive style related to less defiance (e.g., Baudat, Zimmermann, Antonietti, \& Van Petegem, 2016; Van Petegem et al., 2017b; Vansteenkiste et al., 2014). Similarly, previous research among adolescents (aged 15-19 years) also found that a controlling communication style relates to more problem behavior and a higher involvement with deviant peers (e.g., Soenens et al., 2009). Finally, in a longitudinal study among dyads of parents and children (aged 8-15 years), it was found that more controlling parenting as observed during an interaction task predicted increases in excessive gaming one year later (Li, Lo, \& Cheng, 2018). Taken together, a controlling style in particular might create the "forbidden fruit" phenomenon, increasing the child's interest in gaming and the likelihood that the child would defy the rules (cf. Brehm \& Brehm, 1981; Van Petegem, Soenens, Vansteenkiste, \& Beyers, 2015a).

Further, in addition to problematic child behaviors such as defiance and excessive gaming, it is also important to consider indicators of adaptive child adjustment. In a qualitative study among parents of 3-to-9-year old children, it was found that parents are often concerned about their child's potential loss of interest in social play due to digital gaming (Zaman, Nouwen, Vanattenhoven, de Ferrerre, \& Van Looy, 2015). Although children often experience digital games as social activities (e.g., Ferguson \& Olson, 2013; Lenhart et al., 2008; Przybylski et al., 2010), there are persistent stereotypes about the negative consequences of video gaming for children's social functioning in real life (Kowert, Domahidi, Festl, \& Quandt, 2014). Indeed, parents of young children often 
perceive digital games as a primarily solitary activity with little opportunities for interaction with others, and are often concerned about the development of the child's social skills (Wartella et al., 2013). Because the development of social relationships is an important developmental task of childhood (Denham et al., 2003), parents may be particularly worried about this potential disadvantage of digital gaming. However, when making use of controlling strategies, parental efforts to encourage social play (by restricting digital gaming) may potentially create reactance and, thus, backfire by producing the opposite outcome (i.e., less interest in social play) and leading children to isolate themselves in a digital environment (see also Weinstein \& Przybylski, 2019). Indirect evidence is provided by research demonstrating associations between a generally controlling parenting style and children's passive isolation, symptoms of social anxiety, and socially withdrawn behavior, among children ranging in age from kindergarten until 14 years (e.g., Loukas, Paulos, \& Robinson, 2005; Mills \& Rubins, 1998). By contrast, previous research documented positive longitudinal associations between a generally autonomy-supportive parenting style and social adjustment among 5-year-olds (Joussemet, Koestner, Lekes, \& Landry, 2005).

Finally, it is also important to consider the role of the child's age and gender, the parents' gender, and the family's socio-economic status (SES). As for age, one may expect differences in terms of parental restrictive mediation between parents of preschoolers (3-5 years) versus parents of children in primary school (6-9 years). As children grow older, they tend to reason differently about parental legitimate rule-setting and increasingly consider leisure activities such as gaming as personal matters over which parents have limited legitimate authority (e.g., Smetana, 2006). Hence, parents' degree of restrictive mediation about gaming would be expected to decline as children grow older and as they transition into elementary school in particular (Gentile, Nathanson, Rasmussen, Reimer, \& Walsh, 2012; Nikken, Jansz, \& Schouwstra, 2007; Shin \& Huh, 2011). The role of parents' age may be relevant as well, as past research found that parents' age is a consistent predictor of more negative attitudes about digital gaming (Ferguson, 2015b; Przybylski, 2014). Further, previous research also found that the parent's as well as the child's gender is related to the degree of mediation. Specifically, research among parents of children ranging in age between 4 and 18 years generally shows that mothers are often more involved in mediating game use (Kousari \& Mehrabi, 2017; Nikken \& Jansz, 2003, 2006; Nikken et al., 2007), and parents generally have more game-related rules for boys than girls (Nikken \& Jansz, 2014). Previous research on parents' style of mediation did not explicitly examine age or gender differences (Valkenburg et al., 2013). Research on parents' style of rulesetting more generally, however, either found an absence or inconsistent age and gender differences in style of rule-setting during the adolescent years (e.g., Soenens et al., 2009; Van Petegem et al., 2015a; Vansteenkiste et al., 2014). 
Finally, research on parental mediation tends to overlook the broader socio-economic context in which family interactions take place (Clark, 2011; Nathanson, 2015). However, the parents' socio-economic status (SES) may have important repercussions for children's development (Bradley \& Corwyn, 2002). Thereby, parents' educational attainment is often assumed to be a primary indicator of SES (Snibbe \& Markus, 2005). Previous research seems to yield diverging results, however. Specifically, some studies, focusing on parents with children between 2 and 18 years of age, found that parents with a higher level of education regulate their children's television use more intensively than lower-educated parents (Austin, Bolls, Fujioka, \& Engelbertson, 1999; Van der Voort, Nikken, \& van Lil, 1992). Yet, an opposite pattern of results was found for parents' mediation of the digital gaming of their 8-18-year old children, with lower-educated parents being more restrictive (Nikken \& Jansz, 2006). As for the relation with parents' style of mediation, we are not aware of any previous studies. However, lower SES might relate to the use of more controlling and less autonomy-supportive strategies, as the psychological distress caused by economic hardship would render parents vulnerable to the use of more coercive and punitive parenting strategies (e.g., Harvey et al., 2016; Leinonen, Solantaus, \& Punamäki, 2002; McLoyd, 1990).

Although quite a few studies examined mean-level differences in parental mediation as a function of these demographic characteristics, much less research addressed the possible moderating role of these demographic characteristics in the correlates of parents' degree and style of mediation. Thereby, one may especially expect that age would moderate the associations of parents' degree of mediation, with such mediation being particularly important at a younger age (Livingstone, Mascheroni, Dreier, Chaudron, \& Lagae, 2015). Moderation of the correlates of parents' style of mediation is less likely, as research in different contexts typically found that the correlates of an autonomy-supportive and controlling style generalize across children's age or gender and across the family's SES (e.g., Chen, Van Assche, Vansteenkiste, Soenens, \& Beyers, 2015a; Ryan \& Deci, 2000; Ryan et al., 2016).

In the current investigation, we focused specifically on restrictive mediation digital gaming among parents of young children between 3 and 9 years of age, thereby distinguishing between their degree and their (autonomysupportive or) controlling style of mediating. We aimed to examine associations with parents' negative attitudes about games as well as with their perceptions of their child's adjustment, focusing both on negative (i.e., defiance against gaming rules and problematic digital game use) and on positive indicators of child adjustment (i.e., interest in social play). To do so, we tested the theoretical model depicted in Figure 1. An additional aim was to examine the role of SES, the child's age, and the parents' and the child's gender. Thereby, we not only looked into mean- 
level differences, but also tested whether the associations of Figure 1 were moderated by these socio-demographic variables.

\section{Method}

\section{Participants}

Our sample consisted of 762 parents $(82.6 \%$ mothers), who were on average 35.27 years old $(S D=5.65)$. As for educational attainment, the highest earned degree was primary school for $1.5 \%$ of the parents, $41 \%$ secondary school, $40.6 \%$ bachelor's degree, and $16.7 \%$ a master's degree or higher. The target children were on average 5.52 years old $(S D=1.86$, ranging in age between 3 and 9 years $)$ and $55.8 \%$ of the children were girls. The majority of the children (91\%) lived together with both biological parents, who were either married or in a relationship.

\section{Procedure}

The data for this study were taken form a larger project. Specifically, as part of a research project funded by the Belgian government, a large-scale survey was distributed through the mailing list of a child-oriented entertainment company. Parents with a child aged between 3 and 9 years were invited to participate in a study on children's digital gaming. If they had more than one child between 3 and 9 years, parents were instructed to focus on the child that is alphabetically ordered the first. Confidential treatment of the data was guaranteed, and the study was in line with the ethical guidelines of the university. A contest was set up at the end of the survey with prizes provided by the entertainment company. We added two bogus items in order to filter unreliable responses (e.g., "This is a test question, please indicate the answer 'never',); parents who incorrectly answered one of the two questions were removed (Meade \& Craig, 2012). Further, we also removed participants with unreliable responses and those who did not meet the sample requirements (e.g., child's age, or survey administered by a grandparent).

\section{Measures}

Parents' degree and style of restrictive mediation. Parents first reported upon their degree of restrictive mediation, their autonomy-supportive style of mediation, and their controlling style of mediation. This was done through a 15-item scale, which followed a procedure that was developed in the context of parents' degree and style of prohibiting (Soenens et al., 2009; Vansteenkiste et al., 2014). Specifically, parents first rated the degree to which they employed restrictive strategies to mediate their child's digital gaming. Thereby, digital games were defined as a wide range of electronic games ranging from short games played on mobile phones to complex, long lasting games played on a console or computer. Our measure of restrictive mediation was the 5-item restrictive 
mediation subscale (e.g., "I prohibit my child to play certain games") from the parental mediation scale developed by Nikken and Jansz $(2003,2006)$. Directly following each item assessing parents' degree of restrictive mediation, we presented to participants two items that measured their style of mediation. Specifically, after each item came a stem (e.g., "If I would prohibit certain games, I would...”), which was then followed by an item assessing autonomy-supportive style (e.g., “...provide a meaningful explanation and ask what he/she thinks about this”) and one item assessing controlling style (e.g., “...punish my child if he/she still plays the game”). The item stems as well as the items themselves were based upon existing measures assessing parents' autonomy-supportive and controlling communication style for introducing prohibitions (Soenens et al., 2009; Vansteenkiste et al., 2014). Specifically, we adapted the stems and the items to make them amenable for a parent report format and to have them refer to the specific content of the restrictive mediation item. Taken together, in total, 5 items assessed parents' degree of restrictive mediation, 5 items assessed their autonomy-supportive style of mediation and 5 items assessed their controlling style of mediation. All items were rated on a 5-point Likert-type scale ranging from 1 (Completely untrue) to 5 (Completely true). A Confirmatory Factor Analysis (CFA) confirmed the threedimensional structure of the measure, which fitted well with the data, $\chi^{2}(79)=254.50, p<.001, \mathrm{CFI}=.91$, $\mathrm{RMSEA}=.05, \mathrm{SRMR}=.06$. Internal consistencies (Cronbach's alpha) were .65 for degree of restrictive mediation, .69 for autonomy-supportive style, and .72 for controlling style, which was somewhat lower than in other studies making use of these scales (e.g., see Nikken \& Jansz, 2006, for the scale assessing degree of mediation; see Soenens et al., 2009; Vansteenkiste et al., 2014, for the scales assessing style of mediation).

Negative attitudes. Parents filled out a 6-item questionnaire assessing their negative attitudes towards digital gaming ("Digital games are a waste of time”, "Digital games are useless", "I believe that digital games pose a threat to children's development", "Digital games are a meaningful activity” (reverse coded), "I think it is good that children play digital games" (reverse coded), "Playing digital games may be harmful for children”). Items were rated on a 5-point Likert-type scale ranging from 1 (Completely untrue) to 5 (Completely true). The fit of a CFA model was good, confirming the unidimensional structure of the scale, $\chi^{2}(8)=30.61, p<.001, \mathrm{CFI}=$ $.98, \mathrm{RMSEA}=.06, \mathrm{SRMR}=.02$. The scale had a reliability (Cronbach's alpha) of .86.

Perceived interest in social play. Using 3 items, we measured parents' perceptions of the child's interest in social play ("My child likes to play with other children", "My child gets along well with other children", "My child enjoys spending time with other children"). Parents rated the items on a 5-point Likert-type scale $(1=$ Completely untrue, 5 = Completely true). A CFA model yielded a perfect fit to the data, as it was fully identified. Internal consistency (Cronbach's alpha) of the questionnaire was .92. 
Perceived defiance. Further, we assessed parents' perceptions of the child's defiance to the parents' gaming rules, using a 4-item scale (Van Petegem, Vansteenkiste, \& Beyers, 2013; Vansteenkiste et al., 2014). Items were slightly adjusted to a parent-report format and were adapted to a digital gaming context ("My child rebels against the rules about gaming", "My child does exactly the opposite of the rules about gaming I expect him/her to follow", "Rules about gaming are of no concern of my child: he/she does as he/she please", "My child simply disregards the rules about gaming'). A CFA analysis indicated an excellent fit to the data, $\chi^{2}(2)=.77, p=$ $.68, \mathrm{CFI}=1.00, \mathrm{RMSEA}=.00, \mathrm{SRMR}=.00$. The scale had a reliability (Cronbach's alpha) of .87.

Perceived problematic use. We assessed perceived problematic use through a slightly adapted version of the 14-item Video Game Addiction Test (VAT) developed by van Rooij et al. (2012). We adapted items to a parent-report format (e.g., "How often does your child find it difficult to stop gaming?”). Parents answered on a 5point scale, ranging from 1 (Never) to 5 (Very often). A CFA model, which fitted the data well, confirmed the unidimensional structure of the scale, $\chi^{2}(71)=201.79, p<.001, \mathrm{CFI}=.94$, RMSEA $=.04, \mathrm{SRMR}=.05$. The internal consistency (Cronbach's alpha) of the scale was .87.

\section{Data Analyses}

Before examining structural relations between our variables of interest, we first tested for possible differences in our study variables by performing a MANCOVA, with the child's gender, age (3-5 years vs. 6-9 years), the parents' gender, and educational level (secondary education vs. higher education) as fixed factors, and parents' age as a covariate. Given the large sample size, the statistical significance level was set at $p<.01$.

Then, we examined associations between our variables of interest using structural equation modeling (SEM) using Mplus 7.00 (Muthén \& Muthén, 2012). We modeled each variable as a latent variables using parceling. Specifically, for each variable, three parcels were created by randomly selecting items from the scale corresponding to the variable (except for the variable "perceived interest in social play", which was measured using only three items and which was therefore modeled as a latent factor with these three items as indicators). When testing associations between latent variables, parceling has several advantages as compared to item-based solutions, including minimizing the effects of bias factors at the item level, circumventing the typically poor psychometric characteristics of items, and avoiding overall model complexity (Little, Cunningham, Shahar \& Widaman, 2002). Through the use of robust maximum likelihood estimation (MLR), we corrected for nonnormality. In a first step, we examined whether the measurement model fitted the data well. Then, we estimated the structural model depicted in Figure 1. Specifically, we modeled parental negative attitudes as a predictor of parents' degree of restrictive mediation and their autonomy-supportive and controlling style of mediation. Degree 
and style of mediation, in turn, were simultaneously modeled as predictors of the parents' perceptions of the child's interest in social play, defiance, and problematic use, in order to test their unique effects. Variables at the same level were allowed to correlate. Evaluation of model fit was again based on the Comparative Fit Index (CFI), Roots Mean Square Error of Approximation (RMSEA), and Standardized Root Mean Square Residual (SRMR). A CFI higher than .90, RMSEA lower than .10 and SRMR lower than .08 indicate acceptable fit, whereas a CFI higher than .95, RMSEA lower than .08 and SRMR lower than .06 indicate good fit (Marsh, Hau \& Wen, 2004).

Finally, we tested whether associations between our study variables were moderated by the child's gender and age, the parent's gender, and educational level. This was done through a series of multigroup comparisons. In a first step, we tested for measurement equivalence across groups (e.g., boys vs. girls), thereby comparing a freely estimated (or unconstrained) model with a model where factor loadings are set equal across groups. When measurement invariance was obtained (i.e., when constrained and unconstrained model do not differ significantly), we tested for structural equivalence in a second step. Thereby, we compared an unconstrained model (where structural relations were allowed to differ across groups) with a constrained model (where relations were fixed across groups). When testing for both measurement invariance and structural invariance, we compared constrained vs. unconstrained models using the difference-in-chi-square $\left(\Delta \chi^{2}\right)$ and difference-in-CFI $(\Delta \mathrm{CFI})$ statistics. A nonsignificant $\Delta \chi^{2}$ and a $\Delta$ CFI value below .01 would indicate that the difference between models is not significant (Cheung \& Rensvold, 2002).

\section{Results}

Means, standard deviations and correlations between our study variables are presented in Table 1. The multivariate MANCOVA results indicated significant effects for the child's gender $[F(7,718)=6.76, p<.001$, $\left.\eta^{2}=.06\right]$ and age $\left[F(7,718)=11.86, p<.001, \eta^{2}=.10\right]$, but not for the parent's gender $[F(7,718)=1.80, p=.09]$, educational level $[F(7,718)=1.50, p=.16]$, or parents' age $[F(7,718)=1.27, p=.26]$. Subsequent univariate analyses indicated that parents reported higher levels of interest in social play for girls $[F(1,724)=15.89, p<.001$, $\left.\eta^{2}=.02, M_{\text {girls }}=4.71, M_{\text {boys }}=4.56\right]$ and they perceived higher levels of problematic use for boys $[F(1,724)=$ $\left.28.56, p<.001, \eta^{2}=.04, M_{\text {girls }}=1.57, M_{\text {boys }}=1.74\right]$. As for the child's age, univariate analyses indicated that parents of 3-5 year old children reported higher levels of restrictive mediation $\left[F(1,724)=14.80, p<.001, \eta^{2}=\right.$ $\left..02, M_{3-5 \text { years }}=4.03, M_{6-9 \text { years }}=3.83\right]$ but lower levels of perceived problematic use $\left[F(1,724)=57.98, p<.001, \eta^{2}\right.$ $=.07, M_{3-5 \text { years }}=1.52, M_{6-9}$ years $\left.=1.79\right]$, as compared to parents of 6-9 year old children. Given these results, we controlled for children's age and children's gender in our subsequent analyses.

We first estimated the measurement model, which fitted the data well $\left[\chi^{2}(168)=392.74, p<.001, \mathrm{CFI}=\right.$ 
$.96, \mathrm{RMSEA}=.04, \mathrm{SRMR}=.04]$. Then, we estimated the structural model depicted in Figure 1 , which fitted the data well $\left[\chi^{2}(209)=454.08, p<.001, \mathrm{CFI}=.95, \mathrm{RMSEA}=.04, \mathrm{SRMR}=.04\right]$. The final results are presented in

Figure 2. Specifically, we found that parents' negative attitudes towards digital games related to higher scores for controlling style and were unrelated to parents' degree of mediation and autonomy-supportive style. Higher scores for parents' degree of restrictive mediation, in turn, uniquely related to parents perceiving more interest in social play, less defiance and less problematic use among their children. An autonomy-supportive style of mediation did not relate significantly to any of the outcomes. Finally, we also found that, when parents were more controlling when restricting the child's gaming behavior, they were also more likely to perceive more child defiance and more problematic use.

Then, we tested whether these associations were moderated by the child's gender and age, the parent's gender, and educational level, through a series of multigroup analyses. An overview of these analyses is presented in Table 2. Our measures were found to be invariant across child's gender and age, parent's gender, and educational level, as each of the $\Delta \chi^{2}$-values were non-significant and all $\Delta$ CFI-values were below .01 . Moreover, multigroup analyses examining equivalence of the structural model also indicated that the model was not moderated by the children's gender and age, parents' gender, or educational level. In other words, these results suggest that our obtained structural model does not differ significantly across boys vs. girls, 3-5 year old children vs. 6-9 year old children, mothers vs. fathers, or parents with high vs. low educational level.

\section{Discussion}

The digitalization of young children's play poses new challenges for parents (Radesky et al., 2015). The present investigation focused on parents' regulation (i.e., restrictive mediation) of young children's video gaming, thereby distinguishing between parents' degree of restrictive mediation and their (autonomy-supportive or controlling) style of restricting gaming (cf. Valkenburg et al., 2013). Our study indicated that parents who hold more negative attitudes about digital gaming are more likely to use a controlling style when mediating their child's gaming behavior. Moreover, whereas a higher degree of parental restrictive mediation uniquely related to adaptive child outcomes (i.e., less perceived defiance and excessive gaming, more interest in social play), the opposite pattern was found for parents' controlling style of mediation. Finally, these associations held for mothers and fathers, for boys and girls, for younger and older children (i.e., 3-5 years vs. 6-9 years), and for parents with lower and higher levels of education. These results generally add to a growing body of research (e.g., Sanders, Parent, Forehand, Sullivan \& Jones, 2016) on the association between parental perceptions of technology, parenting practices, and children's behavior, showing robust findings across multiple domains of children's technology use 
and across multiple developmental stages.

A first important set of findings pertains to the correlates of parents' degree of restrictive mediation. A recent meta-analysis on the correlates of parental mediation (Collier et al., 2016) indicated that parental restrictive mediation plays a small, but significant and adaptive, role in predicting child outcomes. In line with this, the present study found evidence for unique associations between parents' degree of restrictive mediation and their perceptions of their children's gaming behavior, indicating that parents who reported a greater quantity of restrictions (regardless of their communication style) perceived less problematic use and less defiance against the gaming rules among their children. Moreover, a higher degree of parental restrictive mediation related to positive outcomes outside the gaming context as well, as these parents also reported that their child was more interested in social play with other children. The latter finding suggests that, when parents set limits to children's gaming, children spend more time with other children in real-life play. This is an important finding, as a major concern among parents is that digital games may potentially trigger disinterest in real-life social interactions (Zaman et al., 2015). In general, these findings also converge with findings from the broader socialization literature, showing that parental structure (including clear rules and expectations) is conducive to children's psychosocial development (e.g., Farkas \& Grolnick, 2010). According to Self-Determination Theory, this is because parental structure would support and facilitate children's need for competence, as structuring parents would convey to children standards of conduct, and provide feedback about their progress in meeting such standards (Grolnick \& Pomerantz, 2009; Skinner, Johnson \& Snyder, 2005).

Moreover, in line with research on parents' mediation of adolescents' media use (Weinstein \& Przybylski, 2019; Valkenburg et al., 2013), the present study found that it is important not only to consider the degree of parental restrictive mediation, but also to take into account the parents' style of mediating their child's digital gaming. Indeed, a controlling style consistently and uniquely related to negative child outcomes (i.e., higher levels of perceived defiance and excessive gaming), above and beyond parents' degree of restrictive mediation. In order words, when setting rules and limitations with regards to digital games, it seems important for parents to refrain from using controlling language (e.g., threatening with punishments, or inducing guilt), as doing so seems counterproductive. As previous research among adolescents suggests, this counterproductive effect of a controlling style likely occurs because such a style frustrates children's need for autonomy and, thereby eliciting reactance and increasing the attractiveness of the behavior that one is trying to prevent (Van Petegem et al., 2015a, 2017a; see also Brehm, 1966).

Although parents' autonomy-supportive style was correlated with better child psychosocial adjustment, no 
unique associations were found between an autonomy-supportive style and any of the child outcomes, when taking into account parents' degree and their controlling style of restrictive mediation. This finding is unexpected because several cross-sectional and longitudinal studies among young children documented the beneficial effects of parental autonomy support (e.g., Grolnick, Frodi, \& Bridges, 1984; Grolnick \& Ryan, 1989; Joussemet et al., 2005; Laurin \& Joussemet, 2017; Whipple, Bernier, \& Mageau, 2011). There are several potential explanations for this absence of a relationship. First, we focused on restrictive mediation specifically. It is possible that an autonomy-supportive style is more beneficial in the context of parents' active mediation, where the focus lies more strongly on parents' discussion and exchange about video game content and media use (Nikken \& Jansz, 2006). Second, our items of autonomy support focused quite strongly on the parents' provision of an explanation and on the solicitation of the child's point of view. Yet, at a younger age, appropriate autonomy support might manifest itself in somewhat different types of parental behaviors, such as the parents' recognition of the child's feelings, or helping and encouraging the child to verbalize emotions (e.g., Whipple et al., 2011). Third, it is possible that an autonomy-supportive style would be especially predictive of child outcomes that are not measured in the present study, such as the children's legitimacy perceptions or their internalization (i.e., willing compliance) of the parental rules (cf. Van Petegem et al., 2017a; Vansteenkiste et al., 2014). Future research is needed to examine these hypotheses.

Further, associations between parental attitudes about gaming and parents' degree and autonomysupportive style were non-significant. This could be due to the fact that our study only focused on negative attitudes about gaming. Potentially, having more positive views about the potential benefits of video gaming (e.g., they may help children develop certain skills; Granic et al., 2014) may be related positively to an autonomysupportive communication style. Nevertheless, our model results indicated that parents who hold more negative attitudes about video games tend to be more controlling when mediating their children's gaming behavior. However, in their attempt of protecting their child from these potentially harmful effects of games, parents may ironically contribute to their children's attraction to digital video games (cf. Brehm, 1966). Although parental beliefs about digital games, in general, have evolved positively (Wartella et al., 2013), these findings underscore that it is important to provide a nuanced story about the dangers but also the benefits of children's digital gaming, as playing video games also may have positive implications for children's cognitive, motivational, emotional and social functioning (Granic et al., 2014). When parents develop more nuanced attitudes about gaming, perhaps their inclination to set rules in a controlling fashion will also diminish.

Finally, we examined the role of a number of socio-demographic variables. We found evidence for a 
limited number of mean-level differences, such as lower scores of restrictive mediation among parents of older children (Nikken \& Jansz, 2007; Shin \& Huh, 2011). Thus, it seems that, as children grow older, parents adapt their levels of restrictive mediation to the changing developmental needs (e.g., for more independence about relatively personal issues, such as digital gaming; Eccles et al., 1993; Smetana, 1999, 2006). Yet, more importantly, none of the associations between parents' degree and style of mediation and the child outcomes were moderated by any of the socio-demographic variables. This is important, as it suggests that our findings can be generalized across the different groups that were studied in our investigation. This is also in line with previous research, showing that the implications of autonomy-supportive and controlling parenting strategies generalize across different cultures (e.g., Chirkov \& Ryan, 2001), different age groups (e.g., Laurin \& Joussemet, 2017; Whipple et al., 2011) and across different people with a different socio-economic status (e.g., Chen et al., 2015a). According to Self-Determination Theory, this is because an autonomy-supportive (vs. controlling) style would satisfy (vs. frustrate) human's basic psychological needs for autonomy, relatedness, and competence, which are increasingly shown to be universally important (e.g., Chen et al., 2015b; Soenens, Vansteenkiste, Van Petegem, Beyers, \& Ryan, 2018; Yu, Levesque-Bristol, \& Maeda, 2017).

\section{Limitations and Suggestions for Future Research}

A number of limitations need to be considered. A first important limitation is the cross-sectional study design, which precludes any conclusion about the directionality of effects. For instance, our presented model suggests that a controlling style is predictive of more problematic gaming and more defiance. However, the socialization process is fundamentally transactional in nature, as children also shape their own socialization (Bell, 1968; Sameroff \& Fiese, 2000). In other words, parents' behaviors do not only have implications for a child's functioning, but the child's behavior also affects the parents' behaviors, cognitions, and attitudes. Thus, children's oppositional behavior also may elicit a more controlling style or more negative attitudes about digital games. Hence, future longitudinal research should examine how our central constructs are interrelated over time.

A second limitation is the sole reliance upon parent reports, which may lead to an overestimation of the associations between variables because of shared method variance. Of course, given the young age of our sample, the survey methodology limited us to only explore the parents' perspective. Yet, future research could include different methodologies, including observations (e.g., Kochanska, Coy, \& Murray, 2001).

Third, future research would do well to examine these dynamics in different cultural contexts, as previous research documented cross-national variations in parents' preference for certain mediation strategies (e.g., Kousari \& Mehrabi, 2017; Livingstone et al., 2015). In that respect, Self-Determination Theory may instigate the 
development of new hypotheses, as this theory makes strong claims about the universality of certain underlying mechanisms. Children's satisfaction (vs. frustration) of their psychological needs is assumed to foster (vs. hinder) psychological growth and flourishing across cultures (Ryan \& Deci, 2000). However, different parental behaviors may be experienced somewhat differently in different cultures, and therefore may have different implications for children's functioning (Soenens, Vansteenkiste, \& Van Petegem, 2015). Hence, an interesting avenue for future research would be to examine similarities and differences across different cultural contexts.

Finally, our study focused on only one type of parental mediation, that is, restrictive mediation. However, the literature on parental mediation distinguishes between several types of parental mediation strategies, including co-use (i.e., enjoying a media activity together) and active mediation (i.e., actively discussing media content; e.g., Clark, 2011; Nikken \& Jansz, 2006). Future research would do well to examine different types of parental mediation strategies, thereby distinguishing between the degree of mediation and the autonomy-supportive and controlling style, in order to gain a full picture of the parents' mediation of their children's digital gaming (cf. Valkenburg et al., 2013).

\section{Conflict of Interest}

The authors report no conflict of interests.

\section{Ethics Statement}

All procedures performed involving human participants in this study were in accordance with the ethical standards of the Ghent University Institutional Review Board and with the 1964 Helsinki declaration and its later amendments or comparable ethical standards.

\section{Informed Consent}

All participants were informed and consented their participation in the study.

\section{Author Contributions}

SVP conceived of the study, analyzed and interpreted the data, and wrote the manuscript. EDF coordinated the project and helped in analyzing the data and writing the manuscript. BS and AVR helped with the interpretation of 
the data, and the writing of the manuscript. JVL helped with the coordination and conception of the study, and with the writing of the manuscript. 


\section{References}

Adachi, P. J. C., \& Willoughby, T. (2013). More than just fun and games: The longitudinal relationships between strategic video games, self-reported problem-solving skills, and academic grades. Journal of Youth \& Adolescence, 42, 1042-1052. doi:10.1007/s10964-013-9913-9

Austin, E. W., Bolls, P., Fujioka, Y., \& Engelbertson, J. (1999). How and why do parents take on the tube. Journal of Broadcasting \& Electronic Media, 43, 175-192. doi: 10.1080/08838159909364483

Barber, B. K. (1996). Parental psychological control: Revisiting a neglected construct. Child Development, 67, 3296-3319. doi: $10.2307 / 1131780$

Barber, B. K., Maughan, S. L., \& Olsen, J. A. (2005). Patterns of parenting across adolescence. New Directions for Child and Adolescent Development, 108, 5-16. doi: 10.1002/cd.124

Baudat, S., Zimmermann, G., Antonietti, J.-P., \& Van Petegem, S. (2016). The role of maternal communication style in adolescents' motivation to change alcohol use: A vignette-based study. Drugs: Education, Prevention, \& Policy, 24, 152-162. doi: 10.1080/09687637.2016.1192584

Bell, R. Q. (1968). A reinterpretation of the direction of effects in studies of socialization. Psychological Review, 75, 81-95. doi: 10.1037/h0025583

Böcking, S., \& Böcking, T. (2009). Parental mediation of television: Test of a German-speaking scale and findings on the impact of parental attitudes, sociodemographic and family factors in German-speaking Switzerland. Journal of Children and Media, 3, 286-302. doi: 10.1080/17482790902999959

Bradley, R. H., \& Corwyn, R. F. (2002). Socioeconomic status and child development. Annual Review of Psychology, 53, 371-399. doi:10.1146/annurev.psych.53.100901.135233

Brehm, J. W. (1966). A theory of psychological reactance. San Diego, CA: Academic Press.

Brehm, S. S., \& Brehm, J. W. (1981). Psychological reactance: A theory of freedom and control. New York: Academic Press

Chen, B., Van Assche, J., Vansteenkiste, M., Soenens, B., \& Beyers, W. (2015a). Does psychological need satisfaction matter when environmental or financial safety are at risk? Journal of Happiness Studies, 16, 745-766. doi:10.1007/s10902-014-9532-5

Chen, B., Vansteenkiste, M., ..., \& Verstuyf, J. (2015b). Basic psychological need satisfaction, need frustration, and need strength across four cultures. Motivation \& Emotion, 39, 216-236. doi: 10.1007/s11031-0149450-1 
Cheung, G. W., \& Rensvold, R. B. (2002). Evaluating goodness-of-fit indexes for testing measurement invariance. Structural Equation Modeling, 9, 233-255. doi: 10.1207/S15328007SEM0902_5

Chirkov, V. I., \& Ryan, R. M. (2001). Parent and teacher autonomy-support in Russian and US adolescents: Common effects on well-being and academic motivation. Journal of Cross-Cultural Psychology, 32, 618635. doi: $10.1177 / 0022022101032005006$

Clark, L. S. (2011). Parental mediation theory for the digital age. Communication Theory, 21, 323-343. doi: $10.1111 / \mathrm{j} .1468-2885.2011 .01391 . \mathrm{x}$

Collier, K. M., Coyne, S. M., Rasmussen, E. E., Hawkins, A. J., Padilla-Walker, L. M., Erickson, S. E., \& Memmott-Elison, M. K. (2016). Does parental mediation of media influence child outcomes? A metaanalysis on media time, aggression, substance use, and sexual behavior. Developmental Psychology, 52, 798-812. doi: 10.1037/dev0000108

Coyne, S. M., Padilla-Walker, L. M., Stockdale, L., \& Day, R. D. (2011). Game on... girls: Associations between co-playing video games and adolescent behavioral and family outcomes. Journal of Adolescent Health, 49, 160-165. doi:10.1016/j.jadohealth.2010.11.249

Denham, S. A., Blair, K. A., DeMulder, E., Levitas, J., Sawyer, K., Auerbach-Major, S., \& Queenan, P. (2003). Preschool emotional competence: Pathway to social competence? Child Development, 74, 238-256. doi: $10.1111 / 1467-8624.00533$

Eccles, J. S., Midgley, C., Wigfield, A., Buchanan, C. M., Reuman, D., Flanagan, C., \& Mac Iver, D. (1993). Development during adolescence: The impact of stage-environment fit on young adolescents' experiences in schools and in families. American Psychologist, 48, 90-101. doi: 10.1037/0003-066X.48.2.90

Farkas, M. S., \& Grolnick, W. S. (2010). Examining the components and concomitants of parental structure in the academic domain. Motivation \& Emotion, 34, 266-279. doi: 10.1007/s11031-010-9176-7

Ferguson, C. J. (2013). Violent video games and the Supreme Court: Lessons for the scientific community in the wake of Brown v. Entertainment Merchants Association. American Psychologist, 68, 57-74. doi:10.1037/a0030597

Ferguson, C. J. (2015a). Does media violence predict societal violence? It depends on what you look at and when. Journal of Communication, 65, 1-22. doi: 10.1111/jcom.12129

Ferguson, C. J. (2015b). Clinicians' attitudes toward video games vary as a function of age, gender and negative beliefs about youth: A sociology of media research approach. Computers in Human Behavior, 52, 379386. doi: 10.1016/j.chb.2015.06.016 
Ferguson, C. J., Coulson, M., \& Barnett, J. (2011). A meta-analysis of pathological gaming prevalence and comorbidity with mental health, academic and social problems. Journal of Psychiatric Research, 45, 1573-1578. doi: 10.1016/j.jpsychires.2011.09.005

Ferguson, C. J., \& Konijn, E. A. (2015). She said/he said: A peaceful debate on video game violence. Psychology of Popular Media Culture, 4, 397-411. doi: 10.1037/ppm0000064

Ferguson, C. J., \& Olson, C. K. (2013). Friends, fun, frustration and fantasy: Child motivations for video game play. Motivation and Emotion, 37, 154-164. doi: 10.1007/s11031-012-9284-7

Gentile, D. A., Nathanson, A. I., Rasmussen, E. E., Reimer, R. A., \& Walsh, D. A. (2012). Do you see what I see? Parent and child reports of parental monitoring of media. Family Relations, 61, 470-487. doi: 10.1111/j.1741-3729.2012.00709.x

Granic, I., Lobel, A., \& Engels, R. C. (2014). The benefits of playing video games. American Psychologist, 69, 6678. doi: $10.1037 / \mathrm{a} 0034857$

Griffiths, M. D., Kuss, D. J., Lopez-Fernandez, O., \& Pontes, H. M. (2017). Problematic gaming exists and is an example of disordered gaming: Commentary on: Scholars' open debate paper on the World Health Organization ICD-11 Gaming Disorder proposal (Aarseth et al.). Journal of Behavioral Addictions, 6 , 296-301. doi: 10.1556/2006.6.2017.037

Grolnick, W. S. (2003). The psychology of parental control: How well-meant parenting backfires. Hillsdale, NJ: Lawrence Erlbaum Associates.

Grolnick, W. S, Frodi, A., \& Bridges, L. (1984). Maternal control style and the mastery of motivation of one-yearolds. Infant Mental Health, 5, 72-82. doi: 10.1002/1097-0355(198422)5:2<72::AIDIMHJ2280050203>3.0.CO;2-O

Grolnick, W. S., \& Pomerantz, E. M. (2009). Issues and challenges in studying parental control: Toward a new conceptualization. Child Development Perspectives, 3, 165-170. doi: 10.1111/j.1750-8606.2009.00099.x

Grolnick, W. S., \& Ryan, R. M. (1989). Parental styles associated with children's self-regulation and competence in school. Journal of Educational Psychology, 81, 143-154. doi:10.1037/0022-0663.81.2.143

Grolnick, W. S., \& Seal, K. (2008). Pressured parents, stressed-out kids: Dealing with competition while raising a successful child. Prometheus Books.

Gurland, S. T, \& Grolnick, W. S. (2005). Perceived threat, controlling parenting, and children's achievement orientations. Motivation \& Emotion, 29, 103-121. doi: 10.1007/s11031-005-7956-2 
Gutnick, A. L., Robb, M., Takeuchi, L., \& Kotler, J. (2010). Always connected: The new digital media habits of young children. New York: The Joan Ganz Cooney Center at Sesame Workshop.

Harvey, B., Matte-Gagné, C., Stack, D. M., Serbin, L. A., Ledingham, J. E., \& Schwartzman, A. E. (2016). Risk and protective factors for autonomy-supportive and controlling parenting in high-risk families. Journal of Applied Developmental Psychology, 43, 18-28. doi: 10.1016/j.appdev.2015.12.004

Holloway, D., Green, L., \& Livingstone, S. (2013). Zero to eight. Young children and their internet use. Retrieved from http://www.lse.ac.uk/media@1se/research/EUKidsOnline/EU\%20Kids\%20III/PDFs/Zero_to_eight_Repor t.pdf

Holtz, P., \& Appel, M. (2011). Internet use and video gaming predict problem behavior in early adolescence. Journal of Adolescence, 34, 49-58. doi: 10.1016/j.adolescence.2010.02.004

Jansen, E., Mulkens, S., \& Jansen, A. (2007). Do not eat the red food! Prohibition of snacks leads to their relatively higher consumption in children. Appetite, 49, 572-577. doi: 10.1016/j.appet.2007.03.229

Joussemet, M., Koestner, R., Lekes, N, \& Landry, R. (2005). A longitudinal study of the relationship of maternal autonomy support to children's adjustment and achievement in school. adjustment and achievement in school. Journal of Personality, 73, 1215-1236. doi: 10.1111/j.1467-6494.2005.00347.x

Joussemet, M., Landry, R., \& Koestner, R. (2008). A self-determination theory perspective on parenting. Canadian Psychology, 49, 194-200. doi: 10.1037/a0012754

Kochanska, G., Coy, K. C., \& Murray, K. T. (2001). The development of self-regulation in the first four years of life. Child development, 72, 1091-1111. doi: 10.1111/1467-8624.00336

Kousari, M., \& Mehrabi, M. (2017). Children's video game experiences: Iranian parents' strategies of mediation. International Journal of Social Sciences, 7, 1-14. Retrieved from http://ijss.srbiau.ac.ir/article_10281_633b7eec97dd9cefe944d9c5638c2ca8.pdf

Kowert, R., Domahidi, E., Festl, R., \& Quandt, T. (2014). Social gaming, lonely life? The impact of digital game play on adolescents' social circles. Computers in Human Behavior, 36, 385-390. doi: 10.1016/j.chb.2014.04.003

Laurin, J. C., \& Joussemet, M. (2017). Parental autonomy-supportive practices and toddlers' rule internalization: A prospective observational study. Motivation and Emotion, 41, 562-575. doi: 10.1007/s11031-017-96275

Leinonen, J. A., Solantaus, T. S., \& Punamäki, R.-L. (2002). The specific mediating paths between economic 
hardship and the quality of parenting. International Journal of Behavioural Development, 26, 423-435. doi: $10.1080 / 01650250143000364$

Lenhart, A., Kahne, J., Middaugh, E., Macgill, A. R., Evans, C., \& Vitak, J. (2008). Teens, video games, and civics: Teens' gaming experiences are diverse and include significant social interaction and civic engagement. Pew Internet \& American life Project. Retrieved from https://eric.ed.gov/?id=ED525058.

Li, A. Y. L., Lo, B. C. Y., \& Cheng, C. (2018). It is the family context that matters: Concurrent and predictive effects of aspects of parent-child interaction on video gaming-related problems. Cyberpsychology, Behavior, and Social Networking. doi: 10.1089/cyber.2017.0566

Little, T. D., Cunningham, W. A., Shahar, G., \& Widaman, K. F. (2002). To parcel or not to parcel: Exploring the question, weighing the merits. Structural Equation Modeling, 9, 151-173. doi:

10.1207/S15328007SEM0902_1

Livingstone, S. (2007). Strategies of parental regulation in the media-rich home. Computers in Human Behavior, 23, 920-941. doi:10.1016/j.chb.2005.08.002

Livingstone, S., Görzig, A., \& Ólafsson, K. (2011) Disadvantaged children and online risk. EU Kids Online network, London, UK. Report, EU Kids Online network, London, UK. Retrieved from: http://eprints.lse.ac.uk/39385/

Livingstone, S., \& Helsper, E. J. (2008). Parental mediation of children's internet use. Journal of Broadcasting \& Electronic Media, 52, 581-599. doi: 10.1080/08838150802437396

Livingstone, S., Mascheroni, G., Dreier, M., Chaudron, S., \& Lagae, K. (2015). How parents of young children manage digital devices at home: The role of income, education and parental style. London: EU Kids Online, LSE.

Loukas, A., Paulos, S. K., \& Robinson, S. (2005). Early adolescent social and overt aggression: Examining the roles of social anxiety and maternal psychological control. Journal of Youth and Adolescence, 34, 335345. doi: 10.1007/s10964-005-5757-2

Marsh, H. W., Hau, K., \& Wen, Z. (2004). In search of golden rules: Comment on hypothesis- testing approaches to setting cutoff values for fit indexes and dangers in overgeneralizing Hu and Bentler's (1999) findings. Structural Equation Modeling, 11, 320-341. doi: 10.1207/s15328007sem1103_2

McLoyd, V. C. (1990). The impact of economic hardship on Black families and children: Psychological distress, parenting, and socioemotional development. Child Development, 61, 311-346. doi: 10.1111/j.14678624.1990.tb02781.x 
Meade, A. W., \& Craig, S. B. (2012). Identifying careless responses in survey data. Psychological Methods, 17, 437-455. doi: 10.1037/a0028085

Mills, R. S., \& Rubin, K. H. (1998). Are behavioural and psychological control both differentially associated with childhood aggression and social withdrawal? Canadian Journal of Behavioural Science/Revue Canadienne des Sciences du Comportement, 30, 132-136. doi: 10.1037/h0085803

Muthén, L. K. \& Muthén, B. O. (2012). Mplus User's Guide ( $7^{\text {th }}$ Edition). Los Angeles, CA: Muthén \& Muthén.

Nathanson, A. I. (2001). Parent and child perspectives on the presence and meaning of parental television mediation. Journal of Broadcasting \& Electronic Media, 45, 201-220. doi:10.1207/s15506878jobem4502_1

Nathanson, A. I. (2015). Media and the family: Reflections and future directions. Journal of Children and Media, 9, 133-139. doi: 10.1080/17482798.2015.997145

Nikken, P. \& Jansz, J. (2003). Parental mediation of children's video game playing: A similar construct as television mediation. Paper presented at the Level Up Conference Proceedings: Proceedings of the 2003 Digital Games Research Association Conference, Utrecht.

Nikken, P. \& Jansz, J. (2006). Parental mediation of children's videogame playing: A comparison of the reports by parents and children. Learning, Media and Technology, 31, 181-202. doi: 10.1080/17439880600756803

Nikken, P., \& Jansz, J. (2007). Playing restricted videogames. Journal of Children and Media, 1, 227-243. doi: $10.1080 / 17482790701531862$

Nikken, P., \& Jansz, J. (2014). Developing scales to measure parental mediation of young children's internet use. Learning, Media \& Technology, 39, 250-266. doi:10.1080/17439884.2013.782038

Nikken, P., Jansz, J., \& Schouwstra, S. (2007). Parents' interest in videogame ratings and content descriptors in relation to game mediation. European Journal of Communication, 22, 315-336. doi:

$$
10.1177 / 0267323107079684
$$

Nikken, P., \& Schols, M. (2015). How and why parents guide media use of young children. Journal of Child and Family Studies, 24, 3423-3435. doi: 10.1007/s10826-015-0144-4

Oosting, W., de Kort, Y. A., \& Ijsselsteijn, W. (2012). Positive parents taking action: Parental mediation of children's digital game-play. Paper presented at the e-Youth Conference, Antwerpen, Belgium.

Przybylski, A. K. (2014). Who believes electronic games cause real world aggression? Cyberpsychology, Behavior, and Social Networking, 17, 228-234. doi: 10.1089/cyber.2013.0245

Przybylski, A. K., Rigby, C. S., \& Ryan, R. M. (2010). A motivational model of video game engagement. Review 
of General Psychology, 14, 154-166. doi: 10.1037/a0019440

Przybylski, A. K., \& Weinstein, N. (2017a). Digital screen time limits and young children's psychological wellbeing: Evidence from a population-based study. Child Development. doi: 10.1111/cdev.13007

Przybylski, A. K., \& Weinstein, N. (2017b). A large-scale test of the goldilocks hypothesis: quantifying the relations between digital-screen use and the mental well-being of adolescents. Psychological Science, 28, 204-215. doi: 10.1177/0956797616678438

Przybylski, A. K., Weinstein, N., Murayama, K., Lynch, M. F., \& Ryan, R. M. (2012). The ideal self at play: The appeal of video games that let you be all you can be. Psychological Science, 23, 69-76. doi: $10.1177 / 0956797611418676$

Radesky, J. S., Schumacher, J., \& Zuckerman, B. (2015). Mobile and interactive media use by young children: The good, the bad, and the unknown. Pediatrics, 135, 1-3. doi: 10.1542/peds.2014-2251

Ryan, R. M., \& Deci, E. L. (2000). Self-determination theory and the facilitation of intrinsic motivation, social development, and well-being. American Psychologist, 55, 68-78. doi: 10.1037110003-066X.55.1.68

Ryan, R. M., Deci, E. L., \& Vansteenkiste, M. (2016). Autonomy and autonomy disturbances in self-development and psychopathology: Research on motivation, attachment, and clinical process. In D. Cicchetti (Ed.), Developmental Psychopathology: Volume 1. Theory and Metod (3rd edition, pp. 385-438). New York: Wiley.

Ryan, R. M., Rigby, C. S., \& Przybylski, A. (2009). The motivational pull of video games: A self-determination theory approach. Motivation and Emotion, 30, 344-360. doi: 10.1007/s11031-006-9051-8

Sameroff, A. J., \& Fiese, B. H. (2000). Transactional regulation: The developmental ecology of early intervention. In J. P. Shonkoff \& S. J. Meisels (Eds.), Handbook of Early Childhood Intervention (2 ${ }^{\text {nd }}$ Ed., pp.135159). Cambridge, UK: Cambridge University Press. doi: 10.1017/CBO9780511529320.009

Sanders, W., Parent, J., Forehand, R., Sullivan, A. D., \& Jones, D. J. (2016). Parental perceptions of technology and technology-focused parenting: Associations with youth screen time. Journal of Applied Developmental Psychology, 44, 28-38. doi: 10.1016/j.appdev.2016.02.005

Scharrer, E. (2004). Virtual violence: Gender and aggression in video game advertisements. Mass Communication \& Society, 7, 393-412. doi: 10.1207/s15327825mcs0704_2

Shin, W., \& Huh, J. (2011). Parental mediation of teenagers' video game playing: Antecedents and consequences. New Media \& Society, 13, 945-962. doi: 10.1177/1461444810388025 
Skinner, E. A., Johnson, S., \& Snyder, T. (2005). Six dimensions of parenting: A motivational model. Parenting: Science \& Practice, 5, 175-235. doi: 10.1207/s15327922par0502_3

Smetana, J. G. (1999). The role of parents in moral development: A social domain analysis. Journal of Moral Education, 28, 311-321. doi: 10.1080/030572499103106

Smetana, J. G. (2006). Social-cognitive domain theory: Consistencies and variations in children's moral and social judgments. In M. Killen \& J. Smetana (Eds.), Handbook of moral development (pp. 119-153). Mahwah, NJ: Lawrence Erblaum.

Snibbe, A. C., \& Markus, H. R. (2005). You can’t always get what you want: Educational attainment, agency, and choice. Journal of Personality and Social Psychology, 88, 703-720. doi: 10.1037/0022-3514.88.4.703

Soenens, B., \& Vansteenkiste, M. (2010). A theoretical upgrade of the concept of parental psychological control: Proposing new insights on the basis of self-determination theory. Developmental Review, 30, 74-99. doi: 10.1016/j.dr.2009.11.001

Soenens, B., Vansteenkiste, M., \& Niemiec, C. P. (2009). Should parental prohibition of adolescents' peer relationships be prohibited? Personal Relationships, 16, 507-530. doi: 10.1111/j.1475-6811.2009.01237.x

Soenens, B., Vansteenkiste, M., \& Van Petegem, S. (2015). Let us not throw out the baby with the bathwater: Applying the principle of universalism without uniformity to autonomy-supportive and controlling parenting. Child Development Perspectives, 9, 44-49. doi: 10.1111/cdep.12103

Soenens, B., Vansteenkiste, M., Van Petegem, S., Beyers, W., \& Ryan, R. (2018). How to solve the conundrum of adolescent autonomy? On the importance of distinguishing between independence and volitional functioning. In B. Soenens, M. Vansteenkiste, \& S. Van Petegem (Eds.), Autonomy in Adolescent Development: Towards Conceptual Clarity (pp. 1-32). Psychology Press.

Valkenburg, P. M., Piotrowski, J. T., Hermanns, J., \& Leeuw, R. (2013). Developing and validating the Perceived Parental Media Mediation Scale: A self-determination perspective. Human Communication Research, 39, 445-469. doi:10.1111/hcre.12010

Van der Voort, T. H. A., Nikken, P., \& van Lil, J. E. (1992). Determinants of parental guidance of children's television viewing: A Dutch replication study. Journal of Broadcasting \& Electronic Media, 36, 61-74. doi: $10.1080 / 08838159209364154$

Van Petegem, S., Soenens, B., Vansteenkiste, M., \& Beyers, W. (2015a). Rebels with a cause? Adolescent defiance considered from the perspective of Reactance Theory and Self-Determination Theory. Child Development, 86, 903-918. doi: 10.1111/cdev.12355 
Van Petegem, S., Vansteenkiste, M., \& Beyers, W. (2013). The jingle-jangle fallacy in adolescent autonomy in the family: In search of an underlying structure. Journal of Youth and Adolescence, 42, 994-1014. doi: $10.1007 / \mathrm{s} 10964-012-9847-7$

Van Petegem, S., Vansteenkiste, M., Soenens, B., Beyers, W., \& Aelterman, N. (2015b). Examining the longitudinal association between oppositional defiance and autonomy in adolescence. Developmental Psychology, 51, 67-74. doi: 10.1037/a0038374

Van Petegem, S., Vansteenkiste, M., Soenens, B., Zimmermann, G., Antonietti, J.-P., Baudat, S., \& Audenaert, E. (2017a). When do adolescents accept or defy to maternal prohibitions? The role of social domain and communication style. Journal of Youth and Adolescence, 46, 1022-1037. doi: 10.1007/s10964-016-05627

Van Petegem, S., Zimmer-Gembeck, M., Soenens, B., Vansteenkiste, M., Brenning, K., Mabbe, E., Vanhalst, J., \& Zimmermann, G. (2017b). Does general parenting context modify adolescents' appraisals and coping with parental regulation? The case of autonomy-supportive parenting. Journal of Child and Family Studies, 26, 2623-2639. doi: 10.1007/s10826-017-0758-9

Van Rooij, A. J., Ferguson, C. J., Colder Carras, M., Kardefelt-Winther, D., Shi, J., Aarseth, E., ... \& Deleuze, J. (2018). A weak scientific basis for gaming disorder: Let us err on the side of caution. Journal of Behavioral Addictions, 7, 1-9. doi: 10.1556/2006.7.2018.19

Van Rooij, A. J., Schoenmakers, T. M., van den Eijnden, R. J., Vermulst, A. A., \& van de Mheen, D. (2012). Video game addiction test: validity and psychometric characteristics. Cyberpsychology, Behavior, and Social Networking, 15, 507-511. doi: 10.1089/cyber.2012.0007

Vansteenkiste, M., \& Ryan, R. M. (2013). On psychological growth and vulnerability: Basic psychological need satisfaction and need frustration as a unifying principle. Journal of Psychotherapy Integration, 23, 263280. doi: $10.1037 / \mathrm{a} 0032359$

Vansteenkiste, M., Soenens, B., Van Petegem, S., \& Duriez, B. (2014). Longitudinal associations between adolescent perceived degree and style of parental prohibition and internalization and defiance. Developmental psychology, 50, 229-236. doi: 10.1037/a0032972

Wartella, E., Rideout, V. J., Lauricella, A., \& Connell, S. (2013). Parenting in the Age of Digital Technology: A National Survey. Report of the Center on Media and Human Development, School of Communication, Northwestern University. Retrieved from http://web5.soc.northwestern.edu/cmhd/wpcontent/uploads/2013/05/Parenting-Report_FINAL.pdf 
Weinstein, N., \& Przybylski, A. K. (2019). The impacts of motivational framing of technology restrictions on adolescent concealment: Evidence from a preregistered experimental study. Computers in Human Behavior, 90, 170-180. doi: 10.1016/j.chb.2018.08.053

Whipple, N., Bernier, A., \& Mageau, G. (2011). Broadening the study of infant security of attachment: Maternal autonomy-support in the context of infant exploration. Social Development, 20, 17-32. doi: 10.1111/j.1467-9507.2010.00574.x

Yu, S., Levesque-Bristol, C., \& Maeda, Y. (2017). General need for autonomy and subjective well-being: A metaanalysis of studies in the US and East Asia. Journal of Happiness Studies. Advance online publication. doi: $10.1007 /$ s10902-017-9898-2

Zaman, B., \& Mifsud, C. L. (2017). Young children's use of digital media and parental mediation. Cyberpsychology: Journal of Psychosocial Research on Cyberspace, 11(3). doi: 10.5817/CP2017-3-xx

Zaman, B., Nouwen, M., Vanattenhoven, J., de Ferrerre, E., \& Van Looy, J. (2015). A qualitative inquiry into the contextualized mediation practices of young children's digital media use at home. Journal of Broadcasting \& Electronic Media, 60, 1-22. doi: 10.1080/08838151.2015.1127240 
Tables

\section{Table 1}

Means, Standard Deviations and Correlations among Study Variables

\begin{tabular}{|c|c|c|c|c|c|c|c|c|}
\hline & $M$ & $S D$ & 1. & 2. & 3. & 4. & 5. & 6. \\
\hline 1. Restrictive Mediation & 3.97 & .66 & & & & & & \\
\hline 2. Autonomy-Supportive Style & 3.69 & .62 & $.21 * * *$ & & & & & \\
\hline 3. Controlling Style & 2.93 & .79 & $.25 * * *$ & $-.19 * * *$ & & & & \\
\hline 4. Negative Attitudes & 2.54 & .66 & .01 & -.08 & $.15^{* * *}$ & & & \\
\hline 5. Perceived Interest in Social Play & 4.66 & .53 & $.15 * * *$ & .08 & .00 & -.06 & & \\
\hline 6. Perceived Defiance & 1.69 & .66 & $-.17 * * *$ & $-.14 * * *$ & $.13 * * *$ & $.12 * *$ & $-.24 * * *$ & \\
\hline 7. Perceived Problematic Use & 1.64 & .47 & $-.13 * * *$ & $-.11 * *$ & $.10 * *$ & -.04 & $-.18 * * *$ & $.28 * * *$ \\
\hline
\end{tabular}

Note. $* * p<.01 . * * * p<.001$. 
Table 2

Summary of Multigroup Analyses Examining the Moderating Role of Child's Gender and Age, Parents' Gender, and Educational Level

\begin{tabular}{|c|c|c|c|c|c|c|}
\hline & \multicolumn{3}{|c|}{ Measurement Equivalence } & \multicolumn{3}{|c|}{ Structural Equivalence } \\
\hline & $\Delta \chi^{2}(14)$ & $p$ & $\Delta \mathrm{CFI}$ & $\Delta \chi^{2}(12)$ & $p$ & $\Delta \mathrm{CFI}$ \\
\hline Child's Gender & 14.00 & .45 & .000 & 18.85 & .09 & .002 \\
\hline Child's Age & 21.35 & .09 & .002 & 11.81 & .46 & .002 \\
\hline Parents' Gender & 16.42 & .29 & .001 & 10.57 & .57 & .000 \\
\hline Educational Level & 20.14 & .13 & .001 & 12.79 & .38 & .001 \\
\hline
\end{tabular}


Figures



Figure 1. Theoretical model 


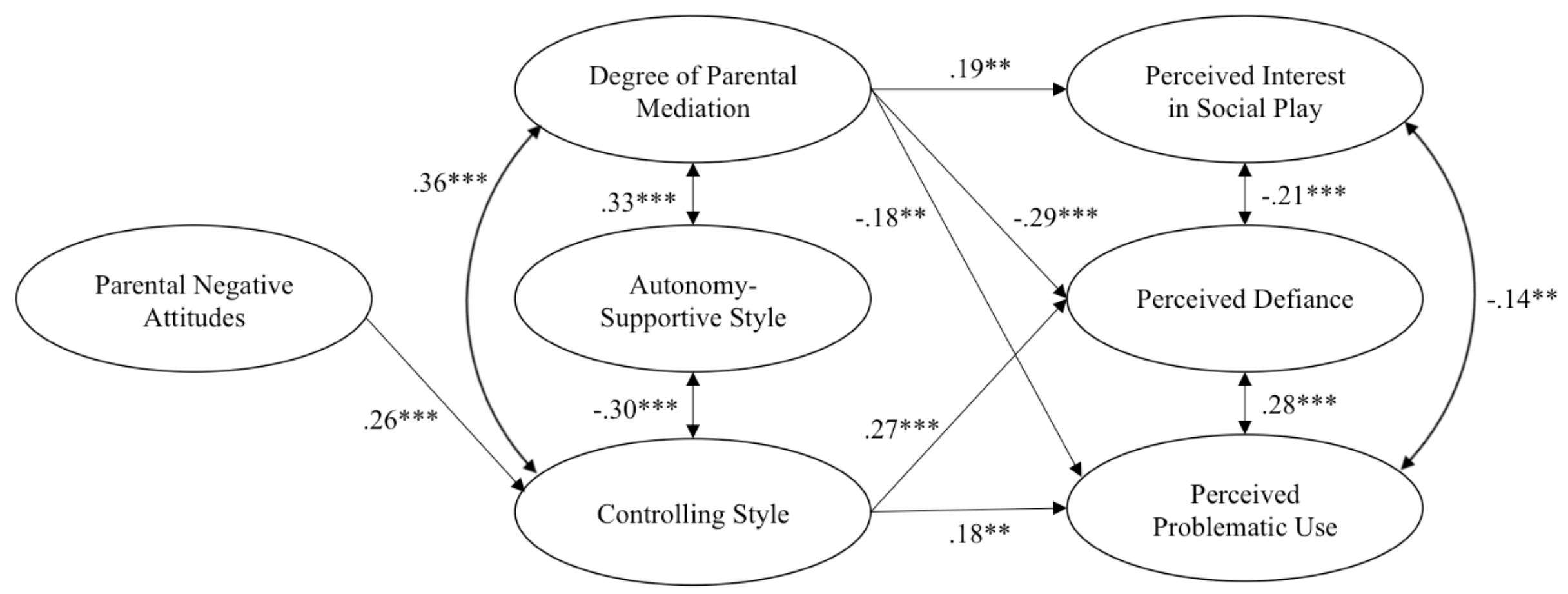

Figure 2. Structural model. For the sake of clarity, effects of control variables are not presented. ${ }^{* *} p<.01 .{ }^{* * *} p<.001$. 